are more dominant in particular areas of public sector work where the environment is changing more rapidly. For example, think of the teachers who have to teach students with different cultural and language backgrounds in a time where teacher shortage is high. A challenge traditionally identified in public administration research concerns employees in public organizations being confronted with high levels of red tape (Bozeman, Reed and Scott 1992; Davis 2013). Furthermore, public sector organizations are characterized by conflicting values and goal ambiguity (Hood 1991; Rainey, Pandey and Bozeman 1995). Employees in public organizations are challenged to balance 'traditional' public values such as integrity, neutrality, and legality, on the one hand with 'business-like' values such as efficiency, effectiveness, and responsiveness on the other hand. As society gets more diverse, representativeness is increasingly difficult to realize, thereby adding to the already "complex set of objectives that public managers and organizations must pursue" (Rainey 2009: 108). Additionally, challenges are associated with the growing expectation to serve citizens and to act in a responsive way. For example, in the field of inspection services we detect an recently intensified shift from command and control based inspection practices to responsive regulation (Rutz, Mathew, Robben and De Bont 2017). This trend leads to changed inspector-inspectee relationships in which inspectors not simply enforce rules and regulations, but are also expected to take into account inspectees' needs and demands (Vigoda 2002).

The observation that working in the public sphere entails challenging and complex situations is certainly not a new one. However, there are still gaps in the literature - some methodological and some more substantive in nature - that have not yet been addressed. For instance, in most studies on this subject employees are seen as having a rather "passive" role: their attitudes are affected by the increasingly challenging working environment. Less attention has been payed to the question which capacities or what (proactive) behaviour are necessary to handle this challenging work environment. In addition, research is likely to benefit from paying attention to the potential positive sides of a challenging public sector work environment, and relinquishing the idea that a demanding and complex work environment is all bad. From a methodological point of view, alternatives to the frequently used cross-sectional survey designs are necessary to reduce the risk of common source bias and to enable insight into whether outcome variables maintain their meaning across different levels of analysis.

This symposium aims to address these gaps in the literature and, through this, to contribute to our knowledge and understanding of public sector employees in a challenging work 
environment. In particular, we aim to shed light on how environmental challenges impact the shared identity, attitudes and behaviour of public sector employees; how public sector employees take charge of continuous change and deal with challenges in their work environment; and how organizations can help employees to deal with work-related challenges.

The remainder of this introduction is structured as follows: First, we provide a short, nonexhaustive review of employees' attitudes in general and employees working in a complex environment in particular. Second, we identify two methodological and two more substantive gaps in the literature on this issue, and explain how this symposium helps to address these gaps. In doing so, we aim to provide directions for future research. We conclude this introduction by summarizing the key findings of the articles included in this symposium.

\section{PUBLIC SECTOR EMPLOYEES IN A CHALLENGING WORK ENVIRONMENT}

Research on public sector employees in general and on individuals working in challenging environments in particular, frequently focuses on employees' attitudes, such as organizational commitment and job satisfaction. How can this interest in attitudes be explained? Attitudes have been found to be solid predictors for organizational-relevant outcomes including performance, attendance and organizational citizenship behaviour, and therefore have been studied by psychologists and organisational behaviour scholars for several decades (see the meta-analysis by Meyer, Stanley, Herscovitch and Topolnytsky 2002). Also in the field of public administration, the question how attitudes can be stimulated and what their outcomes are, has been the subject of extensive research. In this section we provide a short, non-exhaustive review of the literature.

For example, using a large sample of professionals working in the Egyptian health and education sector, Mostafa and Gold-Williams (2015) found that affective commitment can be fostered by high-performance human research practices and that this relationship is partially mediated by public service motivation. In line with this, research by Dick (2011) showed that organizational commitment of a county police force in the UK can be improved by managerial factors. Recent research by Jacobsen and Staniok (2018) found a positive relationship between organizational commitment and employees' perception of their supervisors as transformational leaders among Danish teachers. In addition, organizational socialization tactics, such as formal 
training and mentorships, are found to affect employees' identities, values and motivation, especially those of newcomers in the organization (for a review, see Moyson, Raaphorst, Groeneveld and Van de Walle 2018). Regarding the outcomes of attitudes, Vermeeren, Kuipers and Steijn (2011) found evidence that employees' satisfaction is positively associated with customers' satisfaction. Next to this, a growing body of research has focused on identifying the outcomes of public service motivation (for a review, see Ritz, Brewer and Neumann 2016). Aggregate results suggest that the concept of public service motivation is positively associated with work-related outcomes such as organizational citizenship behaviour and organizational and individual performance.

Studies also address employees' attitudes related to the specificities of the work context of public organizations. For example, goal conflicts and goal ambiguity in public sector organizations are found to have detrimental effects on work motivation and job satisfaction (Wright and Davis 2003; Wright 2004). Gould-Williams et al. (2014) showed that work overload has a negative effect on employees' attitudes. In particular, the authors found that high levels of workload are positively associated with intentions to quit the job and negatively associated with job satisfaction. Others have identified red tape as an important antecedent of public sector employees' job dissatisfaction (Strand and Dore 2009), a decline in job involvement and motivation (Pandey and Scott 2002; Welch and Pandey 2007), increased work alienation (DeHartDavis and Pandey 2005), and feelings of normlessness (Bozeman and Scott 1996). Scholars have also taken into account that working in the specific context of public government inevitably entails

a need to make decisions in the face of value dilemmas (cf. De Graaf, Huberts and Smulders 2016; Hood 1991). The latter is particularly the case when public employees perform their tasks in interaction with others. This includes not only co-workers or public managers. Research also directs attention to coping strategies of public sector professionals in interaction with service users (e.g., Jensen and Andersen 2015) and citizens co-producers (e.g., Jaspers and Steen, 2018).

\section{ADRESSING SOME REMAINING QUESTIONS: FOUR CONTRIBUTIONS}

While the above does not provide a full review of literature on employees' attitudes in demanding work environments, it does show that many questions have already been tackled. A challenging work context is found to have an - often negative - impact on the attitudes of public sector employees. This observation is alarming since attitudes and motivations have been identified as 
important predictors of work-related outcomes. In this section we highlight some methodological and substantial questions that have not yet been fully answered. Moreover, we point out how this symposium helps to address these questions.

First, the studies reviewed above assign a rather "passive" role to employees. The underlying assumption is that employees' attitudes are negatively affected by the challenging work environment. Much less attention is provided to the employees who can actually deal with these challenges. Which characteristics, capabilities, and motives are necessary to stay engaged and committed in such a context? This symposium wants to draw attention to a different perspective in studying employees' attitudes in challenging work environments: one that considers employees as "active" rather than "passive" agents. The rational for this perspective comes from different fields. For example, psychologist and organizational behavioural scholars have identified problem-focused coping strategies (as opposed to passive coping strategies) as a personal resource to deal with changes and complex situations (e.g., Ashford 1988; Martin, Jones and Callan 2006). In his study on changing forms of professionalism, Noordegraaf (2016) stresses the need to stimulate the development of so-called 'organizing and connective capacities' and the ability to be reflective in times of organizational and societal changes. In their recent study on veterinary inspectors, Schott, Steen and Van Kleef (2018) found that having clear job expectations when entering a public sector job helps inspectors to successfully deal with daily work demands such as increasingly aggressive inspectees. Almost two decades ago, Jackson and Stainsby (2000) already predicted that public sector managers of the $21^{\text {st }}$ century would need greater tolerance for ambiguity as well as willingness to take considerable risks, in order to manage new organizational network forms effectively. In this symposium, Homberg, Vogel and Weiherl (XXXX) introduce a new capability that could help individuals dealing with everyday working life. Their empirical research shows that important capabilities of successful organizational change reside within employees who take charge of continuous improvements in order to deal with an increasingly complex and demanding work environment.

Second, a challenging environment is often seen as a risk for employees' well-being in the short term and for organizational performance in the long term. Dissatisfied employees who are not committed to the organization are feared to have less energy or even leave the organization, resulting in a loss of knowledge and increased costs for attracting, selecting and training newcomers. Based on change literature (Kuipers et al. 2014), we argue that it is useful to pay attention to the potential positive sides of a challenging public sector work environment. For 
example, work environment challenges may force us to reconsider entranced patterns of working, leadership behaviour, and the way we train and motivate newcomers. Direct support for the claim that an overly demanding context is not necessarily all bad is provided by Audenaert et al. (XXXX, this issue). The authors found evidence that employees' organizational commitment is not negatively affected by an overly demanding work environment, provided that employees experience a supportive social exchange relationship with the organization. As such their analysis fits well with Karasek's (1979) job-demand model and Bakker and Demerouti's job demandsresources model (2007), which stress the need to balance high demands with the provision of relevant resources.

A first methodological shortcoming of the literature discussed above relates to most studies being cross-sectional in nature, measuring the relationship between work context and individual attitudes by relying on employees' perceptions. Although increasingly used in public administration research (Groeneveld et al. 2015), this type of data and research design enlarges the risk of common source bias and does not allow claiming causal interference (Podsakoff et al. 2003). As a consequence, we cannot rule out the possibility that the relationship between dissatisfaction and conflicting goals, for instance, is the result of unsatisfied employees who experience goals to be more conflicting simply because they invest less energy to sort them out (instead of higher levels of dissatisfaction being the result from conflicting goals). The risks associated with common method bias stress the need to make use of objective data and to use different sources of data (e.g. objective and subjective data from employees, supervisors, and coworkers). If collecting data from different sources is not possible, measuring the dependent and independent variable at different moments in time could be an alternative strategy to reduce common method bias. After all, the created time-lag helps to create psychological separation between independent and dependent variables (see Audenaert, George and Decramer XXX, this issue).

A second methodological limitation of current research relates to research often analysing data at the individual level only. To gain a better understanding of attitudinal phenomena in organizational settings, Demerouti and Bakker (2011) encourage researchers to integrate multiple levels in their research and to analyse whether outcome variables maintain their meaning when including different levels of analysis. On the basis of this, we encourage scholars to research attitudes and behaviours not only at the individual level, but also at the multiple levels (e.g. team level and organizational level) that structure public organizations. This stresses the need for large 
data sets making this type of analysis possible. In this symposium, different contributions address this need for a multi-level approach. Audenaert et al. (XXXX) study the impact of a job level characteristic - the balance between employers' expectations of employees' contributions and the rewards offered - on a variable set at the individual level, namely affective commitment. Additionally, they study the role of an individual level resource. This is the employee's individual perception of a supportive or non-supportive social exchange relationship with the organization, as a buffer to increasing job demands. Also, van Kleef, Steen and Schott (XXX) take into account multiple levels as they study individual inspectors' identity and commitment being influenced by job requirements, the interaction at team-level, organizational level socialization practices, and even interaction with actors (e.g. inspectees) outside the organization. Finally, Reissner (XXX) focuses on the interplay between organizational and collective levels of analysis, rather than looking at individual employee outcomes. She studies how multiple institutional logics affect collective sensemaking in hybrid organizations, which in turn impacts the organizational identity of members as a collective.

\section{OVERVIEW}

Although at first sight the five articles in this symposium seem to address a very broad range of issues, they do have in common that they contribute to our knowledge of public sector employees working in a demanding environment by particularly paying attention to the question how this work environment impacts public sector employees' attitudes and their identity, what (coping) behaviour these employees show in response, or what support the organization can offer. Below we provide a short overview of studies included in this symposium and we explain how these studies contribute to our knowledge regarding (1) the multiple facets of the public sector work environment, (2) effective (coping) behaviour as one way to deal with these challenges at an individual level, and (3) the potential role of organizations in supporting their employees.

The collection of articles in this symposium shows that the challenges of working in the public sector can take different forms. Audenaert et al. (XXX) based their analysis on the high expectations that public sector organizations hold of their employees. They refer to macro-level changes that help explain these increasing demands, such as the introduction of market mechanisms under New Public Management (NPM) or New Public Governance reforms Their 
analysis, however, specifically focuses on jobs becoming 'unbalanced' as increasing expectations about employees' contributions are not necessarily balanced by inducements offered, such as investment in employees' careers, employment security or other resources. The NPM downsizing adagio of 'doing more with less' is a typical example. Interestingly, while their empirical analysis identifies both overdemanding and balanced approaches to the employment relationship in the public organization under study, they do not identify overinvestment where high investments in employees are not coupled with high expected contributions. Also Homberg et al. (XXX) refer to macro-level changes such as a focus on e-government, quality management, and good government as causes of a challenging public work environment. They explore the question why and how organizational members take charge of these macro-level changes at the front-end of the organization. Reissner (XXXX) states that the increasingly demanding context for employees concerns a specific NPM-trend, namely the hybridization of organizations, for example through strategic partnerships or joint ventures that are formed between public and private organizations. Boundaries between public and private logics have become less clear, resulting in confusion and ambiguity about the employees' collective organizational identity. According to Steijn and Van der Voet $(\mathrm{XXX})$, the challenge relates to public sector employees finding less opportunity to interact with service beneficiaries, and to the employees perceiving their work to have less impact due to increasing levels of bureaucratic procedures and administrative regulations. The potential devastating impact of red tape on employees' jobs and attitudes, in turn, highlights the importance of the question to what extent the increased focus on performance, accountability and quality of services in public sector organizations, has brought along with its (over)extended bureaucratic control procedures. The challenge Van Kleef et al.'s (XXX) study, relates to inspectors being demanded to enforce rule compliance and make decisions that are coherent with those taken by their colleagues, yet at the same time they need to be sensitive to the specific situation of the inspectee. Here, trade-offs between competing values ultimately set limits to the ability of rules and regulations, checklists and procedures, and even socialization practices such as training and mentorships to provide a clear answer to what is appropriate behaviour expected in specific situations encountered in the field. This issue has also been discussed extensively in the literature on street-level bureaucrats' discretionary power.

Furthermore, each article in the symposium focuses on explaining (changing) attitudes and the identity of public sector employees by 1) focusing on antecedents of organizational commitment, job satisfaction, role clarity or task mastery; 2) studying the impact of individuals' 
prosocial or public service motivation; 3) looking into proactive and extra-role behaviour; or 4) studying organizational identity as employees' collective sense of self. Additionally, the symposium contributions learn us about the coping behaviour of public sector employees when confronted with challenges. Audenaert et al.'s (XXX) analysis of demanding employment relationships is based on the hypothesis that employees weigh up job demands and job resources offered and, consequently, cope with unbalanced conditions by reducing their affective commitment. In Reissner's (XXX) analysis, employees cope with ambiguity and even incompatibility in the institutional logics of a hybrid organization through collective sensemaking. They seek to shape the organization by comparing the organization with its constituting partners and framing their expectations. The study by Homberg et al. (XXXX) suggests that the so-called "taking charge behaviour" could be an important capability of public employees that enables them to deal with the increasingly complex work environment. The contributions by Van Kleef et al. (XXX) and Steijn and van der Voet $(\mathrm{XXX})$ in particular demonstrate the vulnerability of employees in demanding contexts. Steijn and van der Voet (XXX) find that rather than being a resource that helps public sector employees to cope with the burdens of red tape, prosocial motivation strengthens the negative effects of red tape on job satisfaction. Kleef, et al. (XXX) show how inspectors cope with the complexity of their work by seeking information and feedback both inside their organization and in their contact with inspectees. The resulting processes of informal socialization, however, reveal inspectors' vulnerability to 'capture' by the organizations being inspected.

Third, although not always explicitly discussed, the contributions to this symposium learn us about how public sector organizations can help employees to deal with work-related challenges. Audenaert et al. $(\mathrm{XXX})$ put the spotlight on the job demands and resources and show that organizations, through structuring and managing jobs, affect individual employees' attitudes. Yet at the same time, taking into account employees' perceptions of their relationship with the organization, their analysis demonstrates that the supportive practices of an organization are ultimately filtered by the employees' interpretations. In turn, these interpretations are influenced by the long-term trust that has been built (or that, in contrast, is lacking) in the organizationemployee relationship. Steijn and van der Voet's (XXX) analysis can be considered as a call for organizations. When designing jobs, they need to take into account job impact, job contact as well as time that employees have to spend on dealing with bureaucratic procedures and regulations. A message brought forward by Van Kleef et al. (XXX) is that organizations' intentional practices to 
socialize their employees through selection procedures, providing training programmes or installing mentorships, do have effects. The authors additionally show that these efforts might be supported, yet can also be counteracted by informal socialization outside of the organization's direct sphere of influence. The study by Homberg et al. (xxxx) suggests that not only transformational leadership, but also perceived organizational support and access to resources are important for taking charge behaviour. The capability to deal with a changing work environment can be stimulated by empowering employees and setting a clear vision.

To conclude, safeguarding the well-being of the work force and good organizational performance in demanding work contexts is a difficult act that includes maintaining a healthy balance between demands and resources. However, as we want to close this Introduction to the symposium "Public Sector Employees in a Challenging Work Environment" on a positive note, we argue that challenges in the work environment may also present opportunities for changing entranced patterns of working, leadership behaviour, and the way we train and motivate newcomers for the better. This positive approach to the challenging work environment of many public sector employees is a line of research that deserves more attention.

\section{ACKNOWLEDGEMENT}

We would like to thank the participants of the seminar held in the Hague and hosted by Leiden University, Institute of Public Administration on 6-7 June 2016, where many of the symposium articles were presented and discussed. This seminar was made possible through the financial support of the research program 'Double Bind' VIDI grant with project number 452-10-001 awarded by the Netherlands Organisation for Scientific research (NWO). Special thanks to Daphne van Kleef for her support in organizing the seminar and providing feedback to its participants.

\section{References}

Ashford, S. J. (1988). Individual strategies for coping with stress during organizational transitions. Journal of Applied Behavioral Science, 24, 19-36. 
Audenaert, M., George, B., and Decramer, A. (2018). How a demanding employment relationship relates to affective commitment in public organizations: A multilevel analysis. Public Administration. (This issue)

Bakker, A. B., and Demerouti, E. (2007). The job demands-resources model: State of the art. Journal of managerial psychology, 22(3), 309-328.

Bozeman, B. (2007). Public values and public interest. Counterbalancing economic individualism.

Washington, DC: Georgetown University Press.

Bozeman, B., and Scott, P. (1996). Bureaucratic red tape and formalization: Untangling conceptual knots. The American Review of Public Administration, 26(1), 1-17.

Bozeman, B., Reed, P. N., \& Scott, P. (1992). Red tape and task delays in public and private organizations. Administration \& Society, 24(3), 290-322.

Davis, R. S. (2013). Union commitment and stakeholder red tape: How union values shape perceptions of organizational rules. Review of Public Personnel Administration, 33(4), 365-383.

De Bruijn, H., and Dicke, W. (2006). Strategies for safeguarding public values in liberalized utility sectors. American Review of Public Administration, 84(3), 717-35.

Deem, R. (2001). Globalisation, New Managerialism, Academic Capitalism and Entrepreneurialism

in Universities: is the local dimension still important?. Comparative education, 37(1), 720.

De Graaf, Gjalt, Leo Huberts, and Remco Smulders. 2016. Coping with Public Value Conflicts. Administration and Society 48(9): 1101-27.

DeHart-Davis, L., and Pandey, S. K. (2009). Red tape and public employees: Does perceived rule ysfunction alienate managers?. Journal Of Public Administration Research And Theory, 15 (1), 133-148.

Demerouti, E., and Bakker, A. B. (2011). The job demands-resources model: Challenges for future research. SA Journal of Industrial Psychology, 37(2), 01-09.

Dick, G. P. (2011). The influence of managerial and job variables on organizational commitment in the police. Public administration, 89(2), 557-576.

Gould- Williams, J. S., Bottomley, P., Redman, T. O. M., Snape, E. D., Bishop, D. J., Limpanitgul, T., and Mostafa, A. M. S. (2014). Civic duty and employee outcomes: do 
high commitment human resource practices and work overload matter?. Public Administration, 92(4), 937-953.

Groeneveld, S., Tummers, L., Bronkhorst, B., Ashikali, T., and Van Thiel, S. (2015). Quantitative methods in public administration: Their use and development through time. International Public Management Journal, 18(1), 61-86.

Homberg, F., Vogel, R., and Weiherl, J. (2017). Public Service Motivation and continuous organizational change: Taking charge behaviour. Public Administration. (This symposium)

Hood, C. (1991). A Public Management for All Seasons. Public Administration 69(1): 3-19.

Jacobsen, C. B., and Staniok, C. D. (2018). Sharing The Fire? The Moderating Role of Transformational Leadership Congruence on the Relationship Between Managers' and Employees’ Organizational Commitment. International Public Management Journal, (just-accepted)

Jackson, P. M., \& Stainsby, L. (2000). The public manager in 2010: Managing public sector networked organizations. Public Money and Management, 20(1), 11-16.

Jaspers, S. and Steen, T. (2018 - online first). Realizing Public Values: Enhancement or Obstruction? Exploring Value Tensions and Coping Strategies in the Co-production of Social Care, Public Management Review.

Jensen, U.T., and Andersen, L.B. (2015). Public Service Motivation, User Orientation, and Prescription Behaviour: Doing Good for Society or for the Individual User? Public Administration 93(3): 753-68

Karasek, R.A. (1979). Job Demands, Job Decision Latitude, and Mental Strain: Implications for Job Redesign, Administrative Science Quarterly, 24(2): 285-308;

Kuipers, B. S., Higgs, M., Kickert, W., Tummers, L., Grandia, J., and Van der Voet, J. (2014). The management of change in public organizations: A literature review. Public Administration, 92(1), 1-20.

Martin, A. J., Jones, E. S., and Callan, V. J. (2006). Status differences in employee adjustment during organizational change. Journal of Managerial Psychology, 21, 145-162.

Meyer, J. P., Stanley, D. J., Herscovitch, L., and Topolnytsky, L. (2002). Affective, continuance, and normative commitment to the organization: A meta-analysis of antecedents, correlates, and consequences. Journal of vocational behavior, 61(1), 20-52.

Mostafa, A. M. S., Gould- Williams, J. S., and Bottomley, P. (2015). High- performance human resource practices and employee outcomes: the mediating role of public service

This article is protected by copyright. All rights reserved. 
motivation. Public Administration Review, 75(5), 747-757.

Moyson, S.; Raaphorst, N.; Groeneveld, S. and Van de Walle, S. (2018). Organizational Socialization in Public Administration Research: A Systematic Review and Directions for Future Research, American Review of Public Administration, 48(6), 610-627.

Noordegraaf, M. (2016). Reconfiguring Professional Work: Changing Forms of Professionalism in Public Services. Administration and Society 48(7): 783-810.

Pandey, S. K., and Scott, P. G. (2002). Red tape: A review and assessment of concepts and measures. Journal of public administration research and theory, 12(4), 553-580.

Podsakoff, P. M., MacKenzie, S. B., Podsakoff, N. P., and Lee, J. (2003). Common method biases in behavioural research: A critical review of the literature and recommended Remedies. Journal of Applied Psychology, 88(5), 879-903.

Rainey, H. G. (2009). Understanding and managing public organizations. John Wiley and Sons.

Rainey, H. G., Pandey, S., \& Bozeman, B. (1995). Research note: Public and private managers' perceptions of red tape. Public Administration Review, 567-574.

Reissner, S. C. (2017). 'We are hybrid': members' search for organizational identity in institutionalized public-private partnership. Public Administration. (This issue)

Rutz, S., Mathew, D., Robben, P., \& de Bont, A. (2017). Enhancing responsiveness and consistency: Comparing the collective use of discretion and discretionary room at inspectorates in England and the Netherlands. Regulation \& Governance, 11(1), 81-94.

Schott, C., Steen, T., and Van Kleef, D. D. (2018). Reality Shock and Public Service Motivation: A Longitudinal, Qualitative Study Among Dutch Veterinary Inspectors. International Journal of Public Administration, 1-14.

Scott, W. R. (2008). Lords of the Dance: Professionals as Institutional Agents.” Organization Studies 29 (2): 219-238.

Skelcher, C., and Smith, S. R. (2015). Theorizing hybridity: Institutional logics, complex organizations, and actor identities: The case of nonprofits. Public Administration, 93(2), 433-448.

Strand, V. C., and Dore, M. M. (2009). Job satisfaction in a stable state child welfare workforce: Implications for staff retention. Children and Youth Services Review, 31, 391-397.

Steijn, B., and van der Voet, J. Relational job characteristics and job satisfaction of public sector employees: When prosocial motivation and red tape collide. Public Administration.

Van Kleef, D., Steen, T., and Schott, C. (2018). Informal socialization in public organizations: 
Exploring the impact of informal socialization on enforcement behaviour of Dutch veterinary inspectors. Public Administration. (This issue)

Vermeeren, B., Kuipers, B., and Steijn, B. (2011). Two faces of the satisfaction mirror: a study of work environment, job satisfaction, and customer satisfaction in Dutch municipalities. Review of public personnel administration, 31(2), 171-189.

Vigoda, E. (2002). From responsiveness to collaboration: Governance, citizens, and the next generation of public administration. Public Administration Review, 62, 527-540.

Welch, E. W., and Pandey, S. K. (2007). E-government and bureaucracy: Toward a better understanding of intranet implementation and its effect on red tape. Journal of Public Administration Research and Theory, 17(3), 379-404.

Wright, B. E., and Davis, B. S. (2003). Job satisfaction in the public sector: The role of the work environment. The American Review of Public Administration, 33(1), 70-90.

Wright, B. E. (2004). The role of work context in work motivation: A public sector application of goal and social cognitive theories. Journal of public administration research and theory, 14(1), 59-78. 